\title{
How (not) to Improve the Quality of Universities
}

Dear readers,

in recent years, we have heard about the need to improve the quality of our universities in differently strong waves virtually continuously. How many suggestions have been made on how to reform universities, how much time a lot of people have spent on them, how much has it cost - and the results? The annual cosmetic changes in the funding of schools associated with limitation of number of students in public schools, which only complicate schools' considerations exceeding one-year horizon and bring no benefits. All of this variegated by occasional disputes concerning the granting, or not granting the accreditation.

There are a number of reasons why the reform of universities is more talk than action - apart from political reasons also probably unclarification, which changes actually our universities need. There is no doubt that our universities do not hold the top spots of international charts, and it will take a lot of effort to reach them. On the other hand, I dare say the level of many Czech universities has increased in recent years and, therefore, to say that higher education needs fundamental reform, is very shallow. In addition, it may give rise to the feeling that we can wave a magic wand and get to the top of charts. No one has such an instrument. On the other hand, of course, there exists space for raising the level of universities, but the question is how to go in the right direction.

The main problem is that measuring quality of university is not simple at all. The main outputs of the university can be seen in two areas: Science and research and graduates. There are attempts to measure quality in both areas, but there is a variety of issues and it is difficult to objectively measure quality of the university on their basis. There is no one definite indicator and in an attempt to include more criteria, there will always be dependency on division of importance. Moreover, the difficulty of measuring or assessing objectively the quality of range of output necessarily slips to measuring or assessing what is relatively easily measurable or assessable. Nevertheless, the results of those evaluations express the quality very remotely (e.g., quality of publishing activities is 
measured by the number of publications, rather than by own content and measuring of "quality" of graduates is even more complicated).

When we take difficulty of objective measuring of the quality of the university or of one particular programme into account, we cannot expect that detailed accreditation process can provide quality of higher education. The idea that we can create a body which would be able to objectively and competently assess whether this or that school is able to reach the quality goals of this or that programme is wrong. Taking into consideration the number of schools and disciplines, their diversity and dynamic development of many of them, accreditation body cannot provide such assessment. In addition, in a number of aspects, the problem is the fact that the assessment is carried out by the people of de facto competing schools.

Another recent initiative, which tries to increase the quality of universities, is the Q-RAM project. Already the idea that someone might be able to establish what exactly graduate of a particular programme should know is very controversial. If this keeps an eye on only the essential general scope of core subjects, it will not probably have a great importance - few schools would not fit into it. If we are more specific, we will find out that it is not only difficult to define such scope, but it may constrain schools and hobble the development of new approaches. The development of universities can not be achieved by uniting. Only by the competition of different approaches can be proved which is the best! But - if we assume that we were able to define the scope, how would we monitor their implementation? It will be very easy to copy them to forms of accreditation, so it will not be possible to find anything from them out. And that someone would control how teaching actually meets the written content?

Efforts to improve the quality of higher education through administratively formalised processes are natural. They are relatively easy to implement and a lot of people see them as correct. In my view, however, we cannot expect of them any positive changes in quality of universities and if you include associated costs - both financial and time - we can rather pretend the contrary.

The way to improving the quality of universities will not be easy or short. It will go through the higher responsibility of universities themselves and through the greater demands on the "subscriber of 
outputs" from universities in selecting what graduates or scientific outputs will be taken. There should emerge the different level of schools.

The state as a customer of outputs should put much more emphasis on the level of scientific output and employed university graduates as well. For Example flat-rate requirement on degree for some positions in the state administration, regardless of what kind of education or what kind of school it is, is exactly what supports the low quality of some schools. And the state as the guarantor of the education system? Leave a detailed assessment of the individual programmes, keep an eye rather on how are the individual schools evaluated by "purchasers of outputs", derive from it which schools have a longer term perspective including institutional funding. Fears that good universities do not transform greater responsibility and autonomy into higher quality are less justified than expecting that the state is able to improve it through its formal administrative procedures.

doc. Ing. Petr DVOř́́K, Ph.D.

Dean

Faculty of Finance and Accounting, University of Economics, Prague 